\title{
AN EMPIRICAL STUDY OF THE \\ EFFECT OF LEADERSHIP INFLUENCE ON DECISION OUTCOMES IN \\ DIFFERENT SIZED JURY PANELS*
}

\author{
Beth A. Eakin \\ Arizona State University
}

\begin{abstract}
An experiment was conducted to investigate the effect of direction of leadership influence on decision outcomes requiring a large consensus in groups of six and twelve members. The need for this empirical research was prompted by the recent Supreme Court decision to reduce the size of juries from twelve to six members. One hundred and sixty subjects were randomly assigned to high and low leadership influence in six and twelve member panels and asked to deliberate as jurors on a civil suit. The findings were as follows: (1) direction of leadership had substantial impact on decision outcome, regardless of group size, and (2) leadership in the low direction, i.e., pressure toward lesser monetary compensation, tended to be more successful than toward high compensation. Though these findings are supportive of recent jury reform, some new questions as to the role of leadership in decision making groups such as juries are raised.
\end{abstract}

Traditionally jury panels have been composed of twelve members. Two recent Supreme Court decisions, however, allow Federal District courts and all state courts to adopt a less than twelve member jury panel (Williams $\underline{\mathrm{v}}$. Florida; Colgrove v. Battin). In its decision, the Court ruled that the number twelve is not "magical" and emphasized the point that no difference has been established in the disposition of cases between six and twelve member juries. This major reform is based primarily upon considerations of time, cost and efficiency of court administration and minimally upon the findings of social science (Zeise 1, 1971; Van Dyke, 1975). For the most part, the little

* I would like to thank Professor Richard $H$. Nagasawa for his interest in and helpful suggestions throughout this project. I am also grateful to Joseph Henery, Carolyn S. Wells, Becky Clark and Julia Robinson for their continual help in administering the experiment. In addition, I was spurred on by Jon Van Dyke, Associate Professor at Hastings College of the Law, who helped sustain my belief that there was a need for this research. 
evidence in support of jury reform cones from statistical analys is of court records on decisions made by six and twelve member panels (Cronin, 1958; Morris, 1971; Mills, 1973; Bermant and Coppock, 1973). However, since 1970 an increasing number of empirical studies have been conducted to examine this issue (Ahern, 1972; Anapol, 1973; Kessler, 1973, Nagasawa and Eakin, 1975). Though these findings tend to support the Supreme Court opinion, further evidence is needed before a definitive answer to all aspects of the differences between six and twelve member decision making groups can be given.

Existing social psychological research suggests that patterns of role differentiation change as group size is reduced (e.g., the size of the group appears to affect the emergence of leadership). Moreover, the problem of individual input into the determination of group norms and decision outcomes becomes more difficult as the size of the group increases. That is, as group size is increased, the individual member has less time to speak, more opinions to grapple with and a more elaborate structure of roles to fit into. Reduction in jury size may, in a sense, help ease the difficulty of individuai input into the del iberative process. This "ease" of entry may, however, increase the chances for an individual member to emerge as leader and sway decision outcomes. The purpose of this study is to examine the role of leaders on the decision outcomes of six and twelve member groups in the laboratory. In this context, the present raises the question: Will the presence of a strong leader have more influence on decision outcomes in the six or twelve member panel?

\section{Background}

Social scientists no longer explain leadership effectiveness solely in terms of individual characteristics. Rather, characteristics of the individual and demands of the situation interact somehow so as to allow persons to achieve leadership status (Stogdi11, 1974). During the course of member interaction, groups become structured in terms of roles and positions. Numerous studies have investigated the relationship of role differentiation to group size (Thomas and Fink, 1963). Not only does group size affect the amount of participation per member, but al so the distribution of participation among members. That is, a gap between the top participator or leader and the other members tends to increase proportionally as the size of the group increases (Bales, et al., 1951; Stephan and Mishler, 1952). Other studies have shown that group size affects the quality of interaction. For example, disagreement of opinion among members is more tolerable in larger groups, indicating greater pressures for consensus in smaller groups (Bales and Borgatta, 1955; Slater, 1958; Berkowitz, 1958). The inhibition hypothesis was proposed to account for this phenomenon. Specifically, this hypothes is suggests that as group size is reduced, members feel less free to express conflict because the consequences of alienating one another become psychologically more severe.

Research indicates that as the group becomes larger, it tends to break into subgroups and develop a more rigorous hierarchy of positions--often with each subgroup or coalition developing its own spokesman or leader (Homans, 1950; Miller, 1951; James, 1951; Hare, 1952; 1962). Thus as group size is reduced, there is a decrease in the number of possible relationships by pairs which allows one member to coordinate and influence group activity. Bass and Norton (1951) found it easier for observers to identify leaders in six member discussion groups than in either smaller or larger eyen-sized groups. It may be that differentiation between leader and followers tends not to emerge as 
distinctly in groups of less than six, and that in larger groups differentiation occurs in terms of subgroups.

Studies indicate that smaller groups place fewer demands on the skill of leaders (Hemphil1, 1950), indicating that as group size decreases there is more opportunity for any one individual to adopt a position of leadership. Hare (1952) further found that for decision making groups, leaders in groups of five have more influence on decision outcome than leaders in twelve member groups and that leadership skill is related to amount of influence only in the larger groups. It has been suggested that as groups become larger, a potential leader must attempt more leadership acts in order to achieve the same amount of success (Bass, T960). At least tentatively, this sketch of the relationship of role differentiation to group size suggests that reduction in jury size may inhibit expressions of disagreements and give persistent individuals more opportunity to initiate leadership acts toward group consensus.

\section{Method}

To examine the influence of leadership in different sized decision making groups, an experiment was conducted in which subjects were asked to serve as jurors in the deliberation of a civil case. The design called for six and twelve member groups to deliberate on the same civil case. The independent variables were group size and input of leader in regard to outcome (i.e., a confederate attempted to influence the group decision according to predetermined criteria). The main dependent variable was the monetary compensation arrived at by each panel. The design of the study is shown in Figure 1.

Subjects. One hundred and sixty undergraduate students at Arizona State University were used in this experiment. Subjects were selected on a voluntary basis and randomly assigned to one of four experimental conditions. For purposes of this study five groups of each condition were formed.

Laboratory Setting. A small group laboratory equipped with a two-way mirror was used in this study. The laboratory was partioned into two areas -the "waiting room" and the "conference" area. The waiting room was used for preliminary instructions and debriefing while the conference area was used for the actual deliberation.

Procedure. Subjects were brought into the "waiting room" and informed that they were to participate in a jury-like situation for purposes of better understanding decisions made by juries. Subjects were then directed to the "conference" area and told to sit at tables arranged to form a "V" so that no one person would appear to be in a position of an "obvious" leader (e.g., at the head of the table). A tape recorded version of the facts involved in a civil suit was then played followed by a taped set of standardized instructions. Subjects were also provided with a written copy of the information on the tape. No attempt was made to simulate actual trial procedure since the primary focal point of this study was on group decision making once in progress. After the presentation of the case material, the groups were asked to decide without further instruction how much compensation, if any, should be awarded to the plaintiff. The group was informed that a consensus of 5/6 was required. An initial "secret" ballot was taken before each deliberation. All further balloting was made at intervals decided by the group. The confederate, who was 
instructed to sit in one of several chairs near to where the experimenter operated the tape recorder, was casually asked to be responsible for collecting the ballots after each vote and to take them in to be counted by the experimenter. After each vote, the experimenter immediately informed the group of the range of compensation awarded in the ballots. If a consensus was not achieved, the group was informed of the importance of the juror role and instructed to please continue until a consensus could be reached. Upon completing the deliberation, subjects were asked to fill out a questionnaire. Finally, the experimenter described the study in some detail, introduced the confederate to the other members and answered questions.

Sociometric observations were made while deliberation was in process. This information along with items in the questionnaire provided indicators of group process, member reactions and member perception of leadership.

Case Material. The facts involved in a fictitious civil suit were presented in written and spoken form to the subjects. Two opposing interpretations of the facts were included. The task was in this way ambiguous. No instructions as to the law were given. The case was entitled "Pierce vs. Teletronics" and is summarized below:

John Pierce (age 32) was a computer programmer, employed by Teletronics for eight years, who left to take a better job with Regional Electronics. Shortly after his employment with Regional, Pierce was told by a representative of Teletronics that he was suspected of stealing important programs which the company wanted returned. The manager of Regional was also informed of Pierce's alleged theft and reminded that Teletronics was one of its best customers. The following day Pierce was fired.

Pierce filed suit against Teletronics for $\$ 500,000$, claiming loss of earning power and damage to his reputation because he had not succeeded in finding suitable employment in the area and he had no desire to move away.

Teletronics stated that they had done nothing wrong because it was within their rights to discontinue buying from a customer and that Pierce's reputation had not been damaged because nothing public had been released.

Leadership Manipulation. The leader variable was introduced as "direction of Teadership. That is, for the first set of trials, the leader (a confederate) attempted to argue for a high compensation settlement of not less than $\$ 100,000$ below the maximum $\$ 500,000$ asked for by the plaintiff. In the second set of trials, the leader was instructed to argue for a low decision outcome of not more than $\$ 100,000$. For this purpose the confederate was instructed to use a specified list of high settlement rationales and low settlement rationales. In addition, the confederate was responsible for putting forth the first suggested estimate of damages for the group to focus their discussion upon.

The high settlement position advanced by the confederate was based upon the following rationales:

1. The amount needed to effect monetary restitution of the plaintiff was liberally estimated, e.g., back wages, relocation expenses, and lawyer fees. 
2. Arguments were given in favor of awarding punitive damages, e.g., the "ruined" reputation of the plaintiff and loss of earning power result from wrongdoings on the part of the defendant such as blackballing, coercion, and allocations of theft.

3. A particular ideological bent stressed the need to act decisively in order to deter such arbitrary uses of power by large companies in the future.

The low settlement position to the contrary was based upon the following arguments :

1. Some restitution is in order but conservative estimates of that amount were advanced. Examples: Lawyer fees should be excluded from consideration; plaintiffs always ask for too much.

2. Punitive damages should not be given because little "real" damage had been done to the plaintiff's reputation. Examples: Nothing public was released; the plaintiff could find work in a different industry; winning the suit, no matter how small the settlement, clears the good name of the plaintiff.

3. The ideological overtone here warned against the dangers of unjustly enriching the plaintiff and thereby removing his incentive to work.

Indicators of Group Process. Each group was observed through the two-way mirror, and a record was kept of the number of verbal acts initiated and received by each group member. This provided a measure of the relative participation of members in the deliberation process. Records were also kept of the number of ballots cast by the groups during the period of deliberation and the time of deliberation.

Indicators of Member Reactions. In the post experimental session, subjects were given a questionnaire in which they were asked to give their reactions to the session with respect to level of satisfaction and agreement with the group's decision.

Indicators of Member Perception of Leadership. In addition, subjects were asked to list the name of the person in the group who (1) talked the most, (2) had the best ideas for helping the group reach its decision, (3) did the most to effectively guide the discussion and (4) acted most like the group leader.

\section{Results}

Decision Outcome. A two-way analysis of variance ' was performed on the decision outcomes which are summarized in Table 1 . In terms of the experimental problem, it can be seen that group size had no significant effect on decision outcome, whereas the direction of leadership had a very significant effect $(F=22.16 ; P=>.01)$. The leadership variable accounts for $57 \%$ of the variance $\left(\mathrm{eta}^{2}=.57\right)$. There was no significant interaction effect of the two variables.

Measure of Leadership Success. ${ }^{2}$ Table 2 contains the means of the success ratio 
of each of the leadership conditions. In the high condition, success is measured by the ratio of the final ballot to the original ballot. For example, if the average initial ballot of the group members was $\$ 100,000$ and the average final ballot (including dissenters, if any) was $\$ 150,000$, the success ratio for that group would be $\mathbf{1 . 5}$. However, to measure success in the low condition, it is necessary to use the ratio of the original to the final ballot in order to indicate in a comparable way how many judgments were moved downward after discussion. Thus, anything above 1.0 represents success in the desired direction in units which we can compare. It can be seen that the confederate leader was successful in influencing the direction of the decision outcome in all conditions. The success ratios tend to differ in terms of high and low leadership condition. Greater success occurred in the low experimental condition $(t=1.79 ; p=3.10)$.

Perception of Leadership. Tables 3 and 4 contain the findings with regard to member perception of the confederation on each of four indicators of leadership. Table 3 shows the percentage of group members in the high and low leadership conditions who selected the confederate as the one among them who had the "best ideas," who most effectively "guided the discussion," and as who acted most like the "group leader." On each of these indicators of leadership the confederate was perceived by the members more often in the high leadership condition than in the low condition. The difference between conditions of those perceiving him as having the best ideas was 7.8 percent. The difference between groups increased to about 11 percent in terms of member perception of him as the one who most effectively guided their discussion. Finally, there was a nearly 14 percentage difference between groups as to their perception of him as the group's leader $(z=1.74 ; p=>.05)$. The relationship between group size and perception of the confederate as the "biggest talker" in the group is shown in Table 4. It can be seen that the six member groups perceived this verbal aspect of the leadership role more often than the twelve member groups ( $7.4 \%$ vs. $48 \%$ ) though actually the relative proportion of the confederates interaction was constant accounting for about twice the expected percentage per member in each of the two sized groups $(1 / 3$ vs. $1 / 6)$. A chi-square test of significance showed this relationship to be significant at the .01 level of significance.

Indicators of Group Process. Table 5 presents the means of the six and twelve member groups for each of the three indicators used to measure group process. No difference was observed due to leadership condition. In addition we may observe that the mean number of ballots cast is nearly identical for the six and twelve member groups. The two-sized groups differ by about thirteen minutes in deliberation time though this difference is not statistically significant. As might be expected, the small and large groups do differ in regard to the mean number of verbal interactions initiated by the members. The mean number of interactions in the large groups is about twice that of six member groups (486 vs. 280 ).

Indicators of Member Reactions. Tables 6 and 7 contain the data regarding member reactions to the group's decision. Table 6 shows the relationship between group size and agreement with the decision outcome by leadership direction. The data indicate that members of small groups tend to approve the outcome when they were being pressured "up" toward greater monetary compensation while members of larger groups tend to agree more with the outcome if they were being argued "down." The impact of size and agreement with decision outcome on those subjects reporting a high level of satisfaction can be seen in Table 7. Level of satisfaction seems to be associated with agreement with the decision 
outcome; however, the strength of this relationship is more pronounced and is significant only in the twelve member groups.

\section{Discussion}

The central finding of this study supports the recent Supreme Court decision to allow courts to reduce the size of jury panels, but it also raises some new concerns. The confederate leader had substantial impact on decision outcomes in both the six and twelve member groups. This finding is not supportive of earlier studies (Hemphi11, 1950; Bass and Norton, 1951; Hare, 1952), which suggest that the larger the group, the less opportunity for any one individual to adopt a position of leadership. It should be noted, however, that the earlier research, though consistent, is limited in number. It may be that reductions in group size increase the chances for persons to achieve leadership--but not' under all conditions. Certainly the type of task situation has been recognized as important to the emergence of leadership. This study indicates that for decision making groups, such as juries, it is possible for persistent individuals to assume leadership, i.e., markedily influence outcomes, regardless of group size. The new concern becomes: What aspect of the jury task allows for the confederate's marked effectiveness? For one thin, the jury task lacks in many ways objective criteria for making judgments. Group members must turn to one another for determining the meaning of the information which they collectively face. Decisions are thus based on social cues. In addition, there is the element of consensus -- members must agree. This mutual dependency to establish a more or less consistent standard is known as norm formation. What emerges, according to social judgment literature, e.g., the classic experiments of Sherif (1935) and Asch (1951), is that behavior -in this case the judgments of individuals -- is being altered by the group. And it takes only one confederate to begin gathering support to set such a norm.

It is not quite clear why leadership success is greater in the low direction. It may be that certain cultural influences in our society make it easier for leaders to sway monetary judgments downward. First, there is the problem of identification. Do jurors sees themselves as the one who is getting the money or who is giving it out? It is generally recognized that individuals tend to identify with the institutions which they serve. Thus it may be that jurors, like welfare workers, see themselves in awarding monetary compensation, not as the ones getting the money but as the ones paying it out. In addition, there is a kind of commonly held belief that plaintiffs always ask for substantially more than they expect to receive in civil suits. It could be this kind of infracul tural system of values which gives the leader a certain "edge" in attempting to influence judgments downward. The finding that leadership influence was more keenly felt by members when they were being argued upward further suggests that such arguments may be counter to their initial inclinations.

The inhibition hypothesis may be utilized to explain the findings with the regard to level of satisfaction and member agreement with the decision. This hypothes is suggests that when group size is reduced, physical freedom (e.g., number of chances to participate) is increased while psychological freedom is restricted. The smallness of the group itself allows more members to interact regardless of special skills; but because of this greater "exposure," smaller groups in a sense inhibit expressions of disagreements more than larger groups. As a result, the interaction process in small groups tends to be more expressive and requires less detached exploration of the views of others. Yielding to the views of others may then be more satisfying for 
members than "sticking to their guns." As the size of the group increases, the strength of these affectional or expressive ties decreases and member relationships become more formal. Under such conditions (unlike the small group which is process-oriented) the large group becomes goal oriented. It follows from this that member satisfaction is more related to agreement with the decision outcome in the twelve member groups, than in the six member groups.

The inhibition hypothesis also helps explain why members of small groups tend to agree more with decision outcomes when they are argued "up" while members of large groups tend to approve outcomes when pressured "down". It has been suggested that there is a higher premium placed on yielding behavior in the small groups due to the intensified interpersonal aspects of the group. In addition, we have argued that individuals are subject to certain cultural influences in our society which make it easier for leader success in the low direction. Thus, when small groups are swayed "up," a direction which is in a sense "harder," members more highly value or agree with the outcome because of the heightened group influence and cohesiveness among members required to solve such a hard problem. For the large groups, emphas is is clearly on "getting the job done." Thus, the more expedient course, i.e., to go low, becomes for them the more agreed upon outcome.

Finally, the finding with regard to the impact of group size on perception of leadership suggests that members see the leader as the most talkative more often in six member groups than in twelve member groups. This is not surprising since as size increases, the tendency for members to form coalitions increases and thus the ability of members to distinguish a spokesman for each position diminishes. Small groups are thus better able to make this kind of discrimination between members.

\section{Summary and Conclusion}

The present study was an attempt to take a closer look at the recent Supreme Court decision to reduce the size of juries from twelve to six members within the context of group dynamics. The effect of leadership on decision outcomes in different sized groups was explored in the small group laboratory. One hundred and sixty subjects were randomly assigned to high and low leadership influence in siz and twelve member panels and asked to deliberate as jurors on a civil suit. The findings were as follows:

1. The direction of leadership had an impact on decision outcome, regardless of group size. Leadership in the low direction, i.e., pressure toward lesser monetary compensation tended to be more successful than pressure toward high compensation. In addition, perception of leadership was more keen when members were being pressured toward high compensation outcomes.

2. In terms of member agreement with the decision outcome, the small group members tended to approve the compensation outcome if they were being argued "up" while members of larger groups tended to agree more with the outcome if they were being argued "down." 
3. Perception of the confederate leader as the most talkative varied according to group size. Members of small groups were more likely to identify him than members of large groups though in fact the relative proportion of the leader's verbal comments was constant.

4. The level of member satisfaction and agreement with the decision outcome was associated. The strength of this relationship was more pronounced and significant only in the twelve member groups.

In light of these findings and earlier studies it is concluded that twelve and six member simulated jury panels do not differ significantly in terms of final group decisions. Even though these findings are supportive of recent jury reform, some new questions were raised as to the role of leadership in decision making groups. The direction of influence exerted by leaders, particularly in the low or conservative direction, had substantial impact on outcomes. It was noted that research on the effect of leadership in different sized decision making groups, such as juries, is severely limited. It was suggested that the nature of the ambiguous task and the element of consensus required to solve it, may account for the success of persistent individuals in influencing the judgment of others -- regardless of group size. The implication here is that those jurors who are the most willing to assume the leadership role, e.g., by assertiveness or persistence, may well be a determining factor in the kinds of decisions reached in the jury room.

\section{Footnotes}

1. An instance of a hung jury occurred in the twelve member low leadership condition. The number of cases in this subcell was therefore one less than the other cells. An analysis of variance was computed which involved treating the mean for that subcell as the missing value.

2. The author wishes to thank Steven Snow, Graduate Associate in Mathematics for developing this measure of leadership success.

\section{References}

Ahern, J.M.

1972 "Communication in juries: a study of decision making in different sized groups." Ohio Speech Journal 10:59-63.

Anapol, M,

1973 "Behind locked doors: an investigation of certain trial and jury variables by means of a video taped trial." Paper presented at the 59th Annual Speech Communication Association Convention, New York: New York, Nov, 8-11. 
Asch, S.E.

1951 "Effects of group pressure upon the modification and distortion of judgment." Pp. 177-90 in H. duetzkow (ed.), Groups, leadership and men. Pittsburgh: Carnegie Press.

Bales, R.F., F. L. Strodbeck, T. M. Mills, and M.E. Rosenborough

1951 "Channels of communication in small groups." American Sociological Journal 16 (August) : $461-468$.

Bales, R.F. and E. F. Borgatta

1955 "Size of group as a factor in the interaction profile." In A. P. Hare, E. F. Borgatta and R. F. Bales. Small Groups. New York: Knopf.

Bass, B. M.

1960 Leadership, Psychology and Organizational Behavior. New York: Harper and Row.

Bass, B. M., and F. T. Norton

1951 "Group size and leaderless discussions," Journal of Appl ied Psychology 35(December) : 397-400.

Berkowitz, M.I.

1958 "An experimental study of the relation between group size and social organization." Ph.0. Dissertation. Yale University.

Bermant, B. and R. Coppock

1973 "Outcomes of six and twelve member jury trials: an analysis of 128 civil cases in the State of Washington." Washington Law Review 48:593-596.

Colgrove vs. Battin

197393 S. Ct. 2448.

Cronin, P. M.

1958 "Six member juries in district courts." Boston Bar Journal 2 (April) :27-29.

Hare, A. P.

1952 Handbook of Smal1 Group Research. New York: Free Press.

Hemphill, J.K.

1950 "Relations between the size of the group and the behavior of 'superior' leaders." Journal of Social Psychology 32 (August):11-22.

Homans, G.C.

1950 The Human Group. New York: Harcourt, Brace, and World.

James, $\mathrm{J}$.

1951 "A preliminary study of the size determinant in small group interaction." American Sociological Review 16 (August):474-477.

Kessler, J. B.

1973 "An empirical study of six- and twelve-member jury decision-making process." University of Michigan Journal of Law Reform 6

(Spring): $712-734$. 
Miller, N. E., Jr.

1951 "The effect of group size on decision making discussions." Ph.D. Dissertation. University of Michigan.

Mills, L. R.

1973 "Six-member and tweive-member juries: an empirical study of trial results." University of Michigan Journal of Law Reform 6

(Spring):671-711.

Morris, T. E.

1971 "Florida's six member criminal juries: constitutional, but are they fair?" University of Florida Law Review 23 (Winter):402-409.

Nagasawa, H., and B. Eakin

1975 "The six member jury: reform or folly?" Presented at the 51st annual meeting of the Southwestern and Rocky Mountain Division of the American Association for the Advancement of Science, Los Alamos, New Mexico, April 23-26.

Sherif, M.

1935 "A study of some social factors in perception." Archives of Psychology 27, Number 187.

Slater, P.E.

1958 "Contrasting correlates of group size." Sociometry 21 (June):129-139.

Stephen, F., and G. Mishler

1952 "The distribution of participation in small groups: an exponential approximation." American Sociological Review 17 (October):598-608.

Stogdill, M.

1974 Handbook of Leadership. New York: Free Press.

Thomas, E. J., and C. F. Fink

1963 "Effects of Group Size." Psychological Bulletin 60 (July):371-384.

Van Dyke, Jon

1975 "Juries of Fewer than Twelve." Unpublished manuscript.

Williams vs. Florida

1970399 v.s. 78.

Zeise T, H.

1971 "...And then there were none; the diminution of the Federal jury." University of Chicago Law Review 710 (Summer):713-715. 
120 Kansas Journal of Sociology

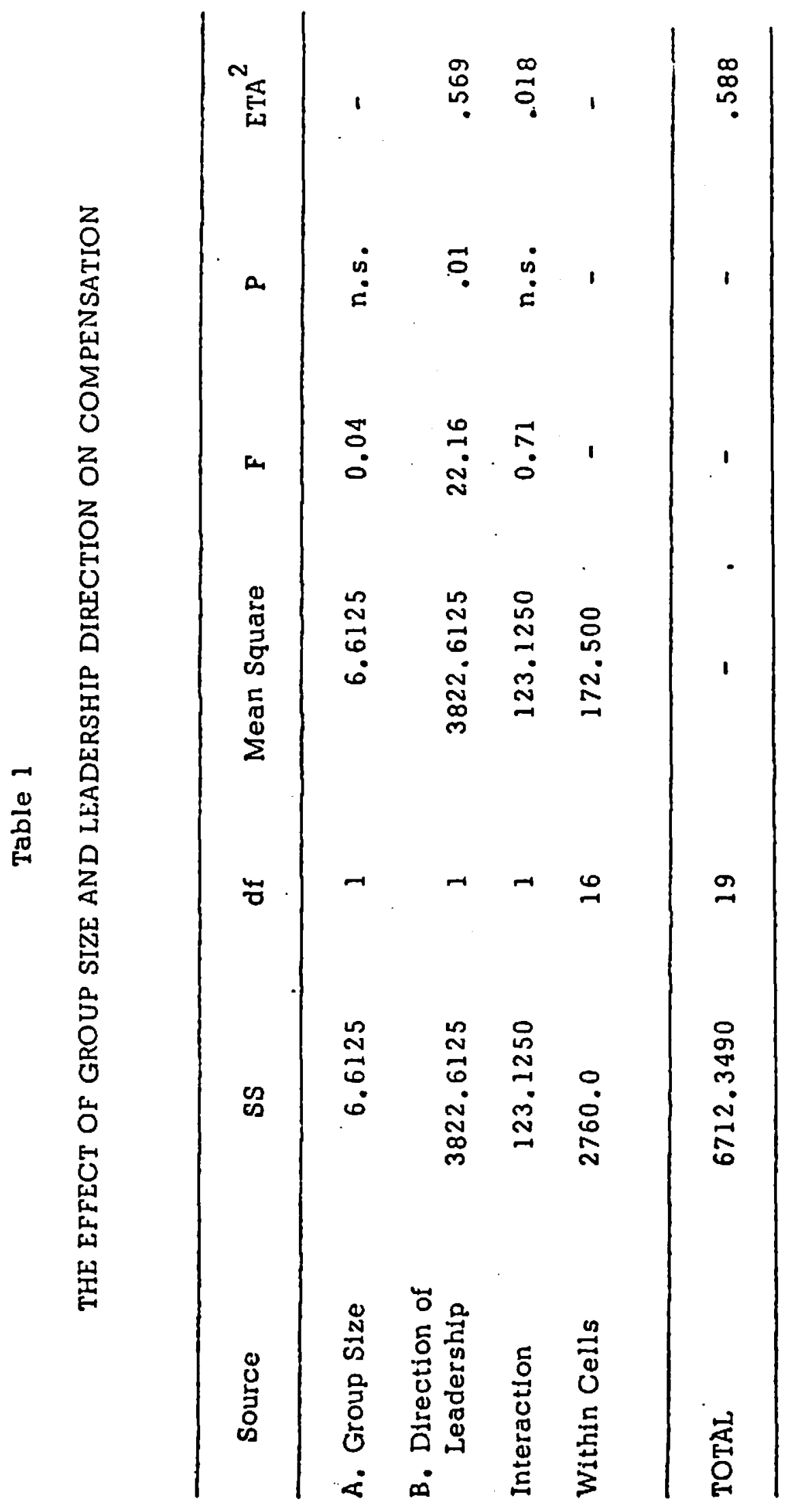


An Empirical Study on the Effect of Leadership Influence 121

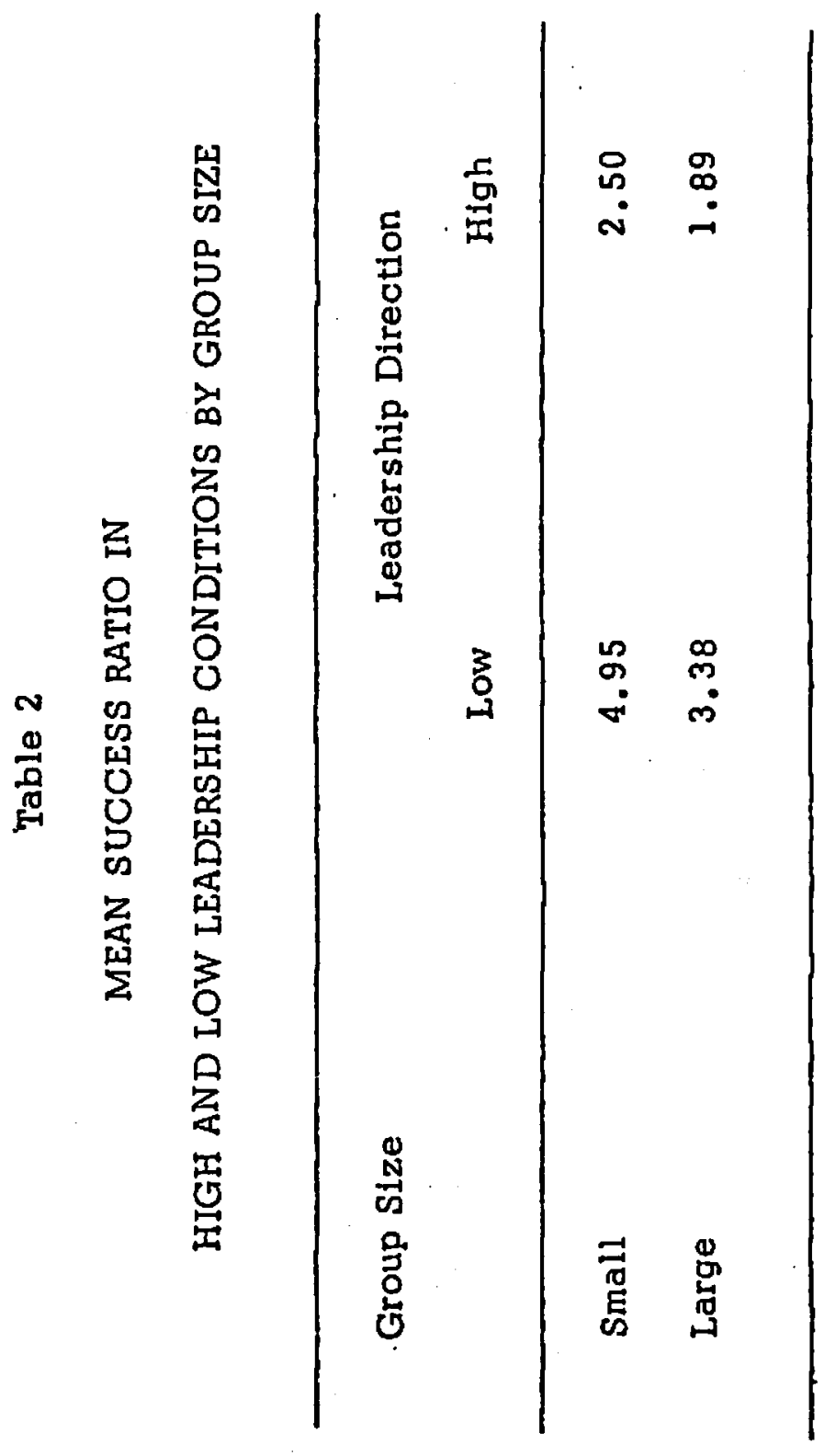




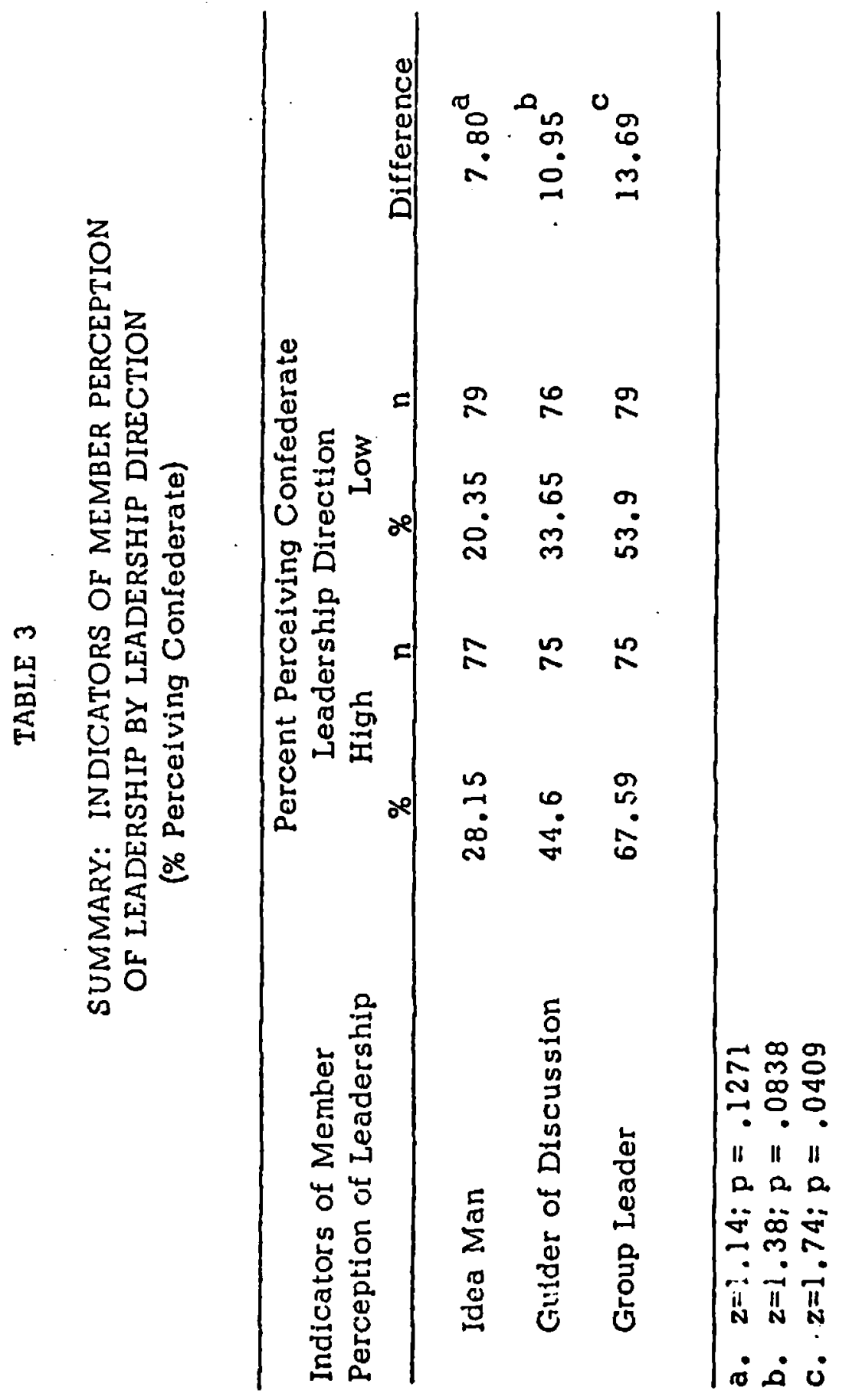


An Empirical Study on the Effect of Leadership Influence 123

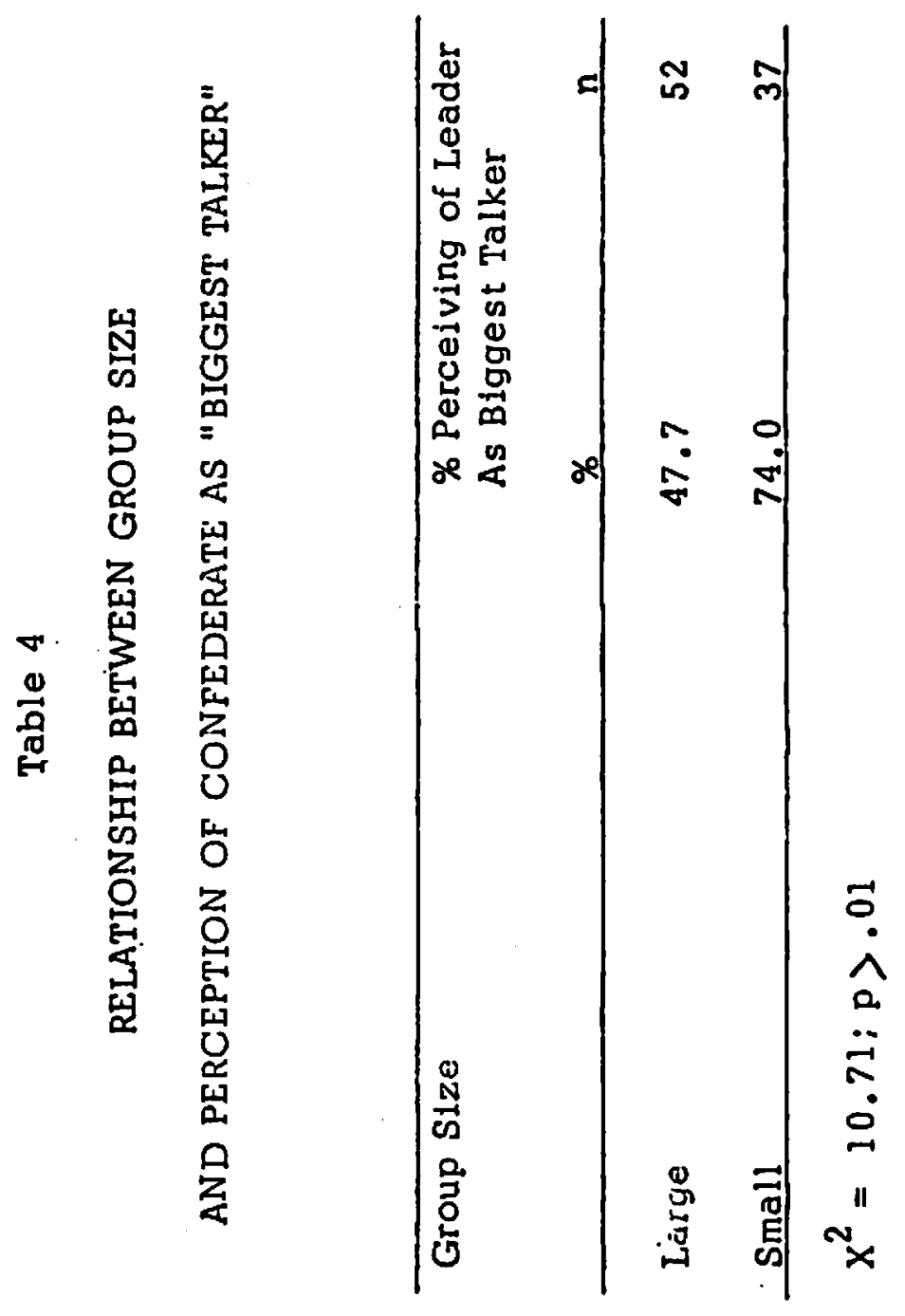




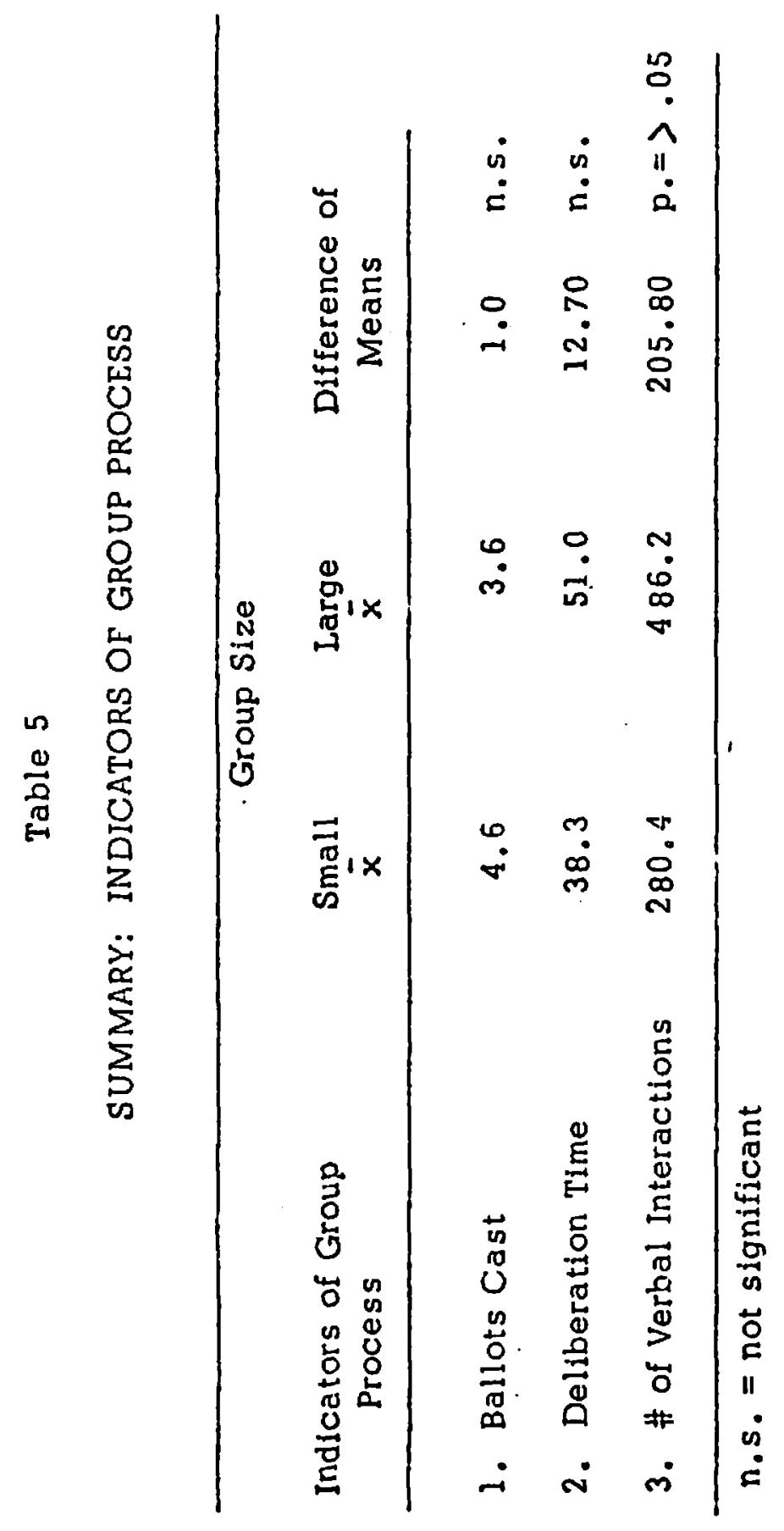


An Empirical Study on the Effect of Leadership Influence 125

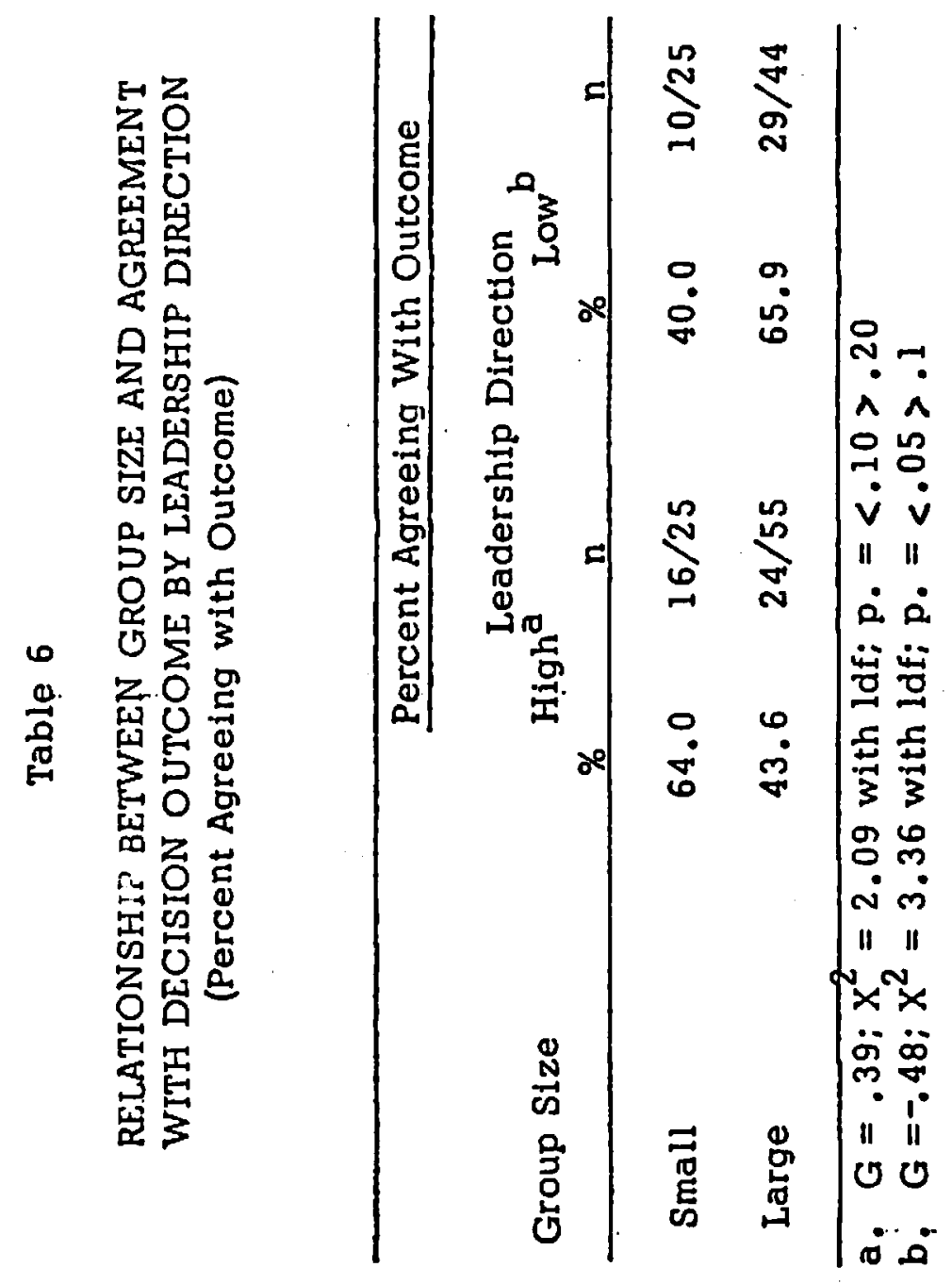




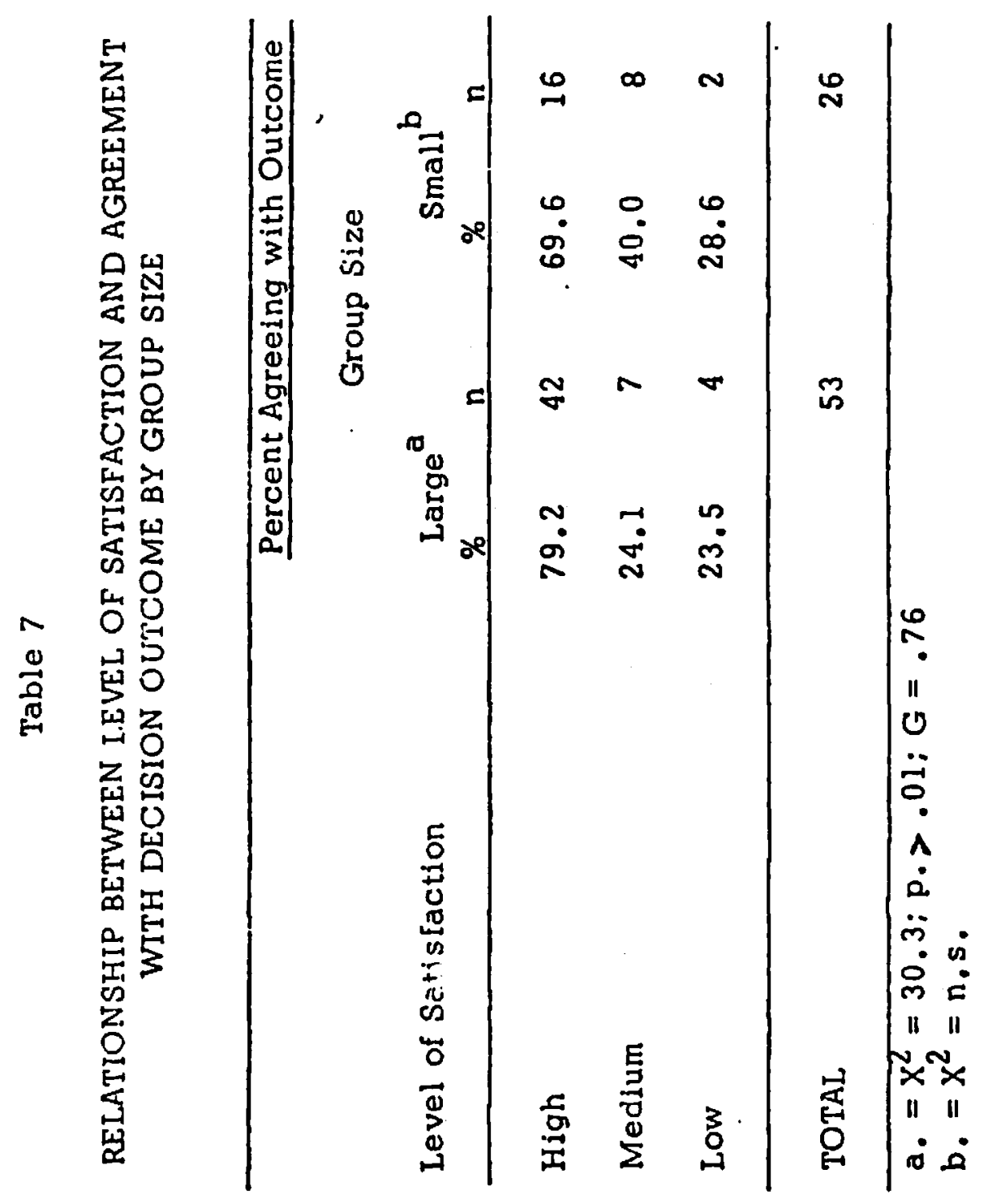

